\title{
O CONCEITO DE LONGUE DURÉE E A PERCEPÇÃO DE MUDANÇACULTURAL EM SOCIEDADES IGUALITÁRIAS: O CASO DA SOCIEDADE SAMBAQUIANA*
}

\author{
Márcia Segal Barbosa-Guimarães** \\ Maria Dulce Gaspar*** \\ Jeanne Cordeiro*** \\ Marcelle Mandarino*** \\ Ivson Graf*** \\ Alice Taboas*** \\ Márcia Farias***
}

\begin{abstract}
O estudo da mudança cultural tem atraído o interesse dos arqueólogos desde os primórdios da história da ciência arqueológica. Sua presença é tão constante nas diferentes concepções teóricas e nas escolas de pensamento que norteiam a Arqueologia - embora tenha sido abordada com graduações diferenciadas e sob ponto de vista diversificado, quer dentro da perspectiva da teoria Evolucionista, dos estudos com cunhos difusionistas e funcionalistas e pela escola processualista - que faz sentido conceituar a disciplina como o estudo da mudança cultural a partir do viés da cultura material.

Dentro desses estudos diversificados, a Arqueologia incorporou importantes contribuições da História e da Antropologia. Especificamente dentro de uma perspectiva temporal, temos uma contribuição significativa da História
\end{abstract}

(*) Projeto de doutoramento “A ocupação pré-colonial da Região dos Lagos, RJ: sistema de assentamento e relações interétnicas entre grupos de pescadores-coletores (sambaquianos) e grupos ceramistas Tupinambá e Jê”. $(* *)$ Doutoranda, Museu de Arqueologia e Etnologia/USP. Bolsista CAPES marcia.segal@terra.com.br. (***) Depto. de Antropologia, Museu Nacional, Universidade Federal do Rio de Janeiro-UFRJ. Maria Dulce Gaspar mgaspar@alternex.com.br; Jeanne Cordeiro jeanne.cordeiro@mn.ufrj.br; Marcelle Mandarino marcellemandarino@gmail.com.br; Ivson Graf venanciograf@yahoo.com.br; Alice Taboas alicetaboas@gmail.com.br; Márcia Farias marciafarias@gmail.com.br
Estrutural e das Mentalidades para a compreensão dos diferentes ritmos em que se dá a mudança cultural. Essa contribuição é percebida (ou acontece) mais precisamente a partir do artigo seminal de Braudel (1958), no qual estabelece a concepção de longue durée, depois de tê-la aplicado ao estudo do "mundo mediterrânico” (Braudel 1949). Assim, é que a Arqueologia introduziu primeiramente essa concepção nos estudos sobre interação social, através de Lamberg-Karlovsky (1985), que se apropriou da concepção de longa duração para compreender o processo de mudança cultural nas sociedades da Mesopotâmia e no planalto iraniano entre 3.440 e 1.600 a.C. Considera-se que a importância da adoção da concepção de longa duração aos estudos sobre mudança social reside na conotação temporal dada ao termo estrutura, como "um fenômeno geográfico, ecológico, técnico, econômico, social, político, cultural e psicológico que permanece constante durante um longo tempo ou que só se desenvolve de maneira quase imperceptível” (Pomian 1993: 113).

É nesse tempo das lentas transformações, o tempo das estruturas, que se busca compreender o processo de desestruturação da sociedade sambaquiana que ocupou o Complexo Lagunar de Saquarema, no estado do Rio de Janeiro, no período entre 4.200 e 1.800 anos AP. Para tanto, estão sendo analisadas, de forma integrada, variáveis ambientais, sociais, econômicas e rituais, coadunando fatores internos e externos que desempenharam papéis importantes no 
processo de mudança que culminou com o desaparecimento dessa sociedade, na Região dos Lagos, por volta de 1.800 anos antes do presente.

\section{Resultados Preliminares}

Os primeiros resultados referem-se à observação das práticas funerárias do grupo que habitou o sambaqui de Itaúnas. ${ }^{1}$ Esse sambaqui localiza-se na restinga entre a lagoa de Saquarema e a praia de Itaúnas, nas coordenadas 22055'62" e 44²9’41", no atual município de Saquarema, um dos municípios da denominada Região dos Lagos. Assenta-se sobre uma duna e encontra-se parcialmente destruído pela construção de uma casa, ocorrida na década de 80. Atualmente, apresenta uma espessura de $80 \mathrm{~cm}$ de camada ocupacional, composta por três camadas arqueológicas: uma mais recente, arenosa, de coloração marrom escuro com grande quantidade de restos faunísticos; outra intermédiária, composta de sedimento argilo-arenoso de coloração avermelhada, com restos faunísticos e sepultamentos humanos; e uma terceira, mais antiga, próxima à base do sítio, composta por sedimento arenoso de coloração cinza claro, com a presença de fogueiras rituais e de raros restos faunísticos. Amostras de material foram enviadas para datação absoluta.

As práticas funerárias observadas nesse sambaqui são decorrentes de dois sepultamentos concomitantes e muito próximos espacialmente.

\section{Sepultamento 1}

Esse sepultamento era primário triplo, composto por indivíduos adultos dispostos em posições distintas:

-O indivíduo 1 encontrava-se em decúbito ventral com a face voltada para oeste e os membros inferiores e superiores estendidos;

(1) Essa pesquisa foi financiada pelo projeto "Do litoral ao interior: padrão de assentamento, processo de interação sociocultural e colonização das populações nativas nos estados do Rio de Janeiro e Espírito Santo”, apoiado pelo CNPq e sob coordenação da Prof ${ }^{\mathrm{a}}$ Maria Dulce Gaspar. Os resultados bioantropológicos estão em fase inicial. tinha como acompanhamento funerário duas pontas ósseas, localizadas junto às costelas do lado direito, e uma placa óssea perfurada.

-O indivíduo 2 encontrava-se em decúbito dorsal, com a face voltada para leste e os membros inferiores e superiores estendidos; tinha por acompanhamento funerário um seixo polido, entre os membros inferiores, e outro, na altura da mão direita. Acompanhavam-no, ainda, duas valvas de Lucina pectinata (Gmelin 1791), posicionadas uma sobre cada órbita da face.

-O terceiro indivíduo encontrava-se em decúbito dorsal com a face voltada para cima e os membros inferiores e superiores estendidos. Faziam parte do seu acompanhamento funerário duas valvas de Lucina pectinata, posicionadas da mesma maneira observada no indivíduo 2, e uma ponta óssea sobre o fêmur direito.

Todos os indivíduos desse sepultamento estavam cobertos por sedimento argilo-arenoso avermelhado, que impregnou não só os ossos, mas também os objetos e a fauna vertebrada e invertebrada que compunham a parafernália ritual.

Esse sepultamento se iniciou com uma fogueira de aproximadamente $25 \mathrm{~cm}$ de diâmetro, assentada diretamente sob a camada arenosa basal do sambaqui. Essa fogueira era composta de raros vestígios de fauna vertebrada e invertebrada e encontrava-se localizada abaixo dos pés do indivíduo 3.

Todos os três indivíduos desse sepultamento tinham oferenda alimentar (peixes e valvas de moluscos) e objetos (pontas ósseas, adorno e seixo polido) que compunham a parafernália ritual. Depois de dispostas as oferendas, os indivíduos foram cobertos primeiramente por um sedimento argilo-arenoso avermelhado, que delimitava o espaço de sepultamento, seguido de uma camada arenosa de coloração preta composta por conchas fragmentadas e ossos faunísticos. Esse sepultamento foi delimitado por estacas, dispostas ao redor da área funerária acompanhando a mancha avermelhada. Possivelmente esse conjunto de estacas deveria suportar uma estrutura leve.

A partir da disposição dos corpos podem ser observadas duas características nesse sepultamento: a primeira refere-se à disposição, 
em um único sepultamento, de três indivíduos, o que indica a existência de algum tipo de relação entre eles, que foi reforçada por ocasião da morte; a segunda, contudo, permite observar que, embora esses indivíduos partilhassem algum tipo de relação, compondo um "grupo de afinidade", o que lhes possibilitava um sepultamento conjunto, o posicionamento diferenciado dos corpos indicava a necessidade também de reforçar a individualidade de cada um dos mortos, remetendo, possivelmente, a diferenças de status.

\section{Sepultamento 2}

O segundo sepultamento era primário simples composto por um indivíduo, jovem ou infantil, disposto em decúbito ventral, tendo os membros inferiores e superiores estendidos e a face voltada para oeste. Acompanhava um seixo polido posicionado acima da cabeça .

O sepultamento se iniciou com duas fogueiras assentadas diretamente sob a camada arenosa basal do sambaqui. Parte da bacia do indivíduo foi posicionada próxima a uma das fogueiras, sendo a cabeça disposta próximo da outra fogueira.

Oferenda alimentar e alguns objetos também faziam parte da parafernália ritual. Após o posicionamento do corpo e das oferendas, o indivíduo foi, então, coberto com sedimento arenoso preto seguido de uma camada preta composta por restos faunísticos fragmentados. Delimitando esse espaço ritual, estacas foram posicionadas a sua volta e, para individualizá-lo do sepultamento 1 , foi espargida uma tênue e estreita faixa de areia branca na borda do sepultamento.
Nota-se a distinção entre os dois sepultamentos, principalmente no tocante à presença de sedimento avermelhado no sepultamento 1.

\section{Conclusão}

Os dados relacionados às práticas que envolvem o ritual funerário estão sendo considerados os mais seguros para uma análise a partir da perspectiva da longa duração, visto envolverem 0 sistema de crenças do grupo sambaquiano em questão. As práticas funerárias, recorrentes ao longo do tempo, se caracterizam pela construção de um mound para receber os mortos composto, principalmente, por material faunístico - moluscos e peixes; por uma delimitação do espaço para receber o corpo através de estacas, sedimento diferenciado da matriz do sambaqui e fogueiras; e pela presença de oferendas mortuárias (alimentos e objetos).

Nesse sentido, a transformação nas práticas funerárias dos grupos sambaquianos que ocuparam o Complexo Lagunar de Saquarema ao longo de 2.400 anos BP serão um forte componente na compreensão do processo de desestruturação dessa sociedade.

Aos dados obtidos a partir da pesquisa efetivada no sambaqui de Itaúnas serão correlacionados aqueles fornecidos pelos estudos realizados nos sambaquis da Beirada, Moa e Pontinha desenvolvidos por Kneip \& Machado (1992; 1993), Kneip et al. (1995), Machado (2001) e Machado \& Kneip (1994).

\section{Agradecimentos}

A Angela Buarque pelas sugestões e pela revisão final do texto.

\section{Referências bibliográficas}

BRAUDEL, F.

1949 Le Méditerranée et le monde méditerranéen à l'époque de Philippe II. Paris: A. Colin.

1958 Histoire et sciences sociales. La longue durée. Annales E.S.C, 4: 725-753.

KNEIP, L.M.; MACHADO, L.M.C.

1992 Cremação e outras práticas funerárias em sítios de pescadores-coletores pré-históricos do litoral de Saquarema, RJ. Boletins, Série Ensaios, IAB, 5: 1-42.

Os ritos funerários das populações pré- históricas de Saquarema, RJ: sambaquis da Beirada, Moa e Pontinha. Documento de Trabalho, Rio de Janeiro, 1: 1-76.

KNEIP, L.M.; MACHADO, L.M.C.; CRANCIO, F.

1995 Ossos humanos trabalhados e biologia esqueletal das populações pré-históricas de Saquarema, RJ. Documento de Trabalho, Rio de Janeiro, 3: 13-38.

LAMBERG-KARLOVSKY, C.

1985 The longue durée of the ancient Near East. J-L.Huot; M. Yon; Y. Calvet (Eds.) De 
Notas-GUIMARÃES, M.S.B; GASPAR, M.D.; CORDEIRO, C.; MANDARINO, M.; GRAF, I.; TABOAS, A.; FARIAS, M. O conceito de longue durée e a percepção de mudança cultural em sociedades igualitárias: o caso da sociedade sambaquiana. Rev. do Museu de Arqueologia e Etnologia, São Paulo, 15-16: 445-448, 2005-2006.

l'Índus aux Balkans, Recueil Jean Deshayes. Paris, Editions Recherche sur les civilisations: 55-72.

MACHADO, L.C.

2001 Os sepultamentos, contextos arqueológicos e dados bioesqueletais. Documento de Trabalho, Rio de Janeiro, 5: 71-79.

\section{MACHADO, L.M.C.; KNEIP, L.M.}

1994 Padrões dentários, dieta e subsistência das populações dos sambaquis de Saquarema, RJ. Revista de Arqueologia, 8 (1): 45-57.

\section{POMIAN, K.}

1993 História das estruturas. J. Le Goff (Org.) A História Nova. Rio de Janeiro, Martins Fontes: 95-123.

Recebido para publicação em 15 de junho de 2006. 